\title{
Chemical Assay of Thiamphenicol and Chloramphenicol
}

\author{
Takashi Uesugi, ${ }^{1 a)}$ Ryohei Hori, and Takaichi Arita ${ }^{1 b}$ \\ Meiji College of Pharmacy ${ }^{1 a}$ and Faculty of Pharmaceutical \\ Sciences, Hokkaido University ${ }^{1 b)}$
}

(Received September 12, 1972)

\begin{abstract}
Spectrophotometric and colorimetric methods for the assay of thiamphenicol (TP) and their application to that of chloramphenicol (CP) are described.

The spectrophotometric method is based upon the reaction of TP with alkali to produce hydrolyzed TP, D-threo-2-amino-3-p-methylsulfonylphenyl-1,3-propanediol, which then converted to $p$-methylsulfonylbenzaldehyde by periodate oxidation.

The other is a colorimetric determination of the aldehyde with APHS reagent (diethanolamine salt of azobenzenephenylhydrazinesulfonic acid). The new reagent, in comparison to the free acid, has the advantages in the stability on storage both in crystalline and solution state and in the solubility in some solvents.
\end{abstract}

Thiamphenicol(TP), D-threo-2,2-dichloro-N-[ $\beta$-hydroxy- $\alpha$-(hydroxymethyl)- $p$-(methylsulfonyl)phenethyl]acetamide, is a potent antibacterial agent. ${ }^{2)}$

Relatively little is known about the biotransformation of this drug. In view of the clinical importance of TP, the authors have been studying on its biotransformation.

In this paper, a rapid ultraviolet (UV) method and a colorimetric method for the assay of $\mathrm{TP}$ and chloramphenicol(CP) in biological materials are described.

In the UV method, TP and $\mathrm{CP}$ can be very simply and rapidly converted into $p$-methylsulfonylbenzaldehyde(MSBA) and $p$-nitrobenzaldehyde (NBA) respectively by a method similar to that described by McChesney, et al. ${ }^{3)}$ These aldehydes are extracted with ethylene dichloride and measured spectrophotometrically.

The colorimetric assay is based on the measurement of the color produced by the reaction of the aldehyde with azobenzenephenylhydrazinesulfonic acid. ${ }^{4}$

The standard procedures of these methods were established by investigating some factors which were concerned with the formation of the aldehydes and the development of the final color.

\section{Experimental}

Materials and Reagents_— TP, kindly supplied by Eisai Co., Ltd., was recrystallized from water, mp $165-166^{\circ}$. CP having $\mathrm{mp}$ of $150-151^{\circ}$ was used. MSBA was prepared from $\mathrm{TP}^{3}$ ) and recrystallized from EtOH, mp $160^{\circ}$. Azobenzenephenylhydrazinesulfonic acid diethanolamine salt (APHS) was prepared as follows: Azobenzenephenylhydrazinesulfonic acid $(0.01 \mathrm{~mole})$, freshly prepared from aniline by the method of Troger, et al.,$\left.{ }^{5}\right)$ and diethanolamine $(0.01$ mole) were dissolved in $10 \mathrm{ml}$ of hot $90 \%(\mathrm{v} / \mathrm{v}) \mathrm{MeOH}$, and rapidly filtrated. On cooling, yellow crystals separated; mp 151-152 . Anal. Calcd. for $\mathrm{C}_{16} \mathrm{H}_{23} \mathrm{O}_{5} \mathrm{~N}_{5} \mathrm{~S}: \mathrm{C}, 48.35$; $\mathrm{H}, 5.83 ; \mathrm{N}, 17.62$. Found: $\mathrm{C}, 48.00 ; \mathrm{H}, 5.75 ; \mathrm{N}, 17.44$.

APHS Reagent- $0.025 \%(\mathrm{w} / \mathrm{v})$ solution of APHS in $\mathrm{MeOH}$ (reagent grade). It should be kept in a cold and dark place, and is valid for one week.

$\mathrm{H}_{2} \mathrm{SO}_{4}$ Reagent- $-12 \%(\mathrm{v} / \mathrm{v})$ solution of $\mathrm{H}_{2} \mathrm{SO}_{4}$ (reagent grade) in $\mathrm{MeOH}$.

HCl Reagent- $\mathrm{MeOH}$ is saturated with dry $\mathrm{HCl}$ gas at $0^{\circ}$, and the solution is then diluted to the concentration of $10 \%(\mathrm{w} / \mathrm{v})$.

1) Location: a) 1-35, Nozawa, Setagaya-ku, Tokyo; b) Kita-12, Nishi-6, Sapporo.

2) J. Laplassotte and M. Brunaud, Thérapie, 16, 101 (1961).

3) E.W. McChesney, J.M. Shekosky, H.W. Eckert, and R.F. Koss, J. Pharm. Sci., 49, 28 (1960).

4) F. Feigle, "Spot Test in Organic Analysis," 6th ed., Elsevier Publishing Company, 1960, p. 228.

5) J. Tröger and W. Hille, Arch. Pharm., 244, 309 (1906). 


\section{Result}

\section{Methods}

UV Method-In a glass-stoppered test tube, $1 \mathrm{ml}$ of sample solution and $1 \mathrm{ml}$ of $1 \mathrm{~N}$ $\mathrm{NaOH}$ solution are placed. The tube is heated in a boiling water bath for $10 \mathrm{~min}$, and then cooled to room temperature. One $\mathrm{ml}$ of $1 \mathrm{M} \mathrm{NaH}_{2} \mathrm{PO}_{4}, 5 \mathrm{ml}$ of ethylene dichloride and $3 \mathrm{ml}$ of $0.5 \% \mathrm{NaIO}_{4}$ solution are added to the mixture. In this procedure, the $\mathrm{NaIO}_{4}$ solution should be added as quickly as possible. The mixture is shaken mechanically for $10 \mathrm{~min}$ and then centrifuged for $2 \mathrm{~min}$. The absorbance of the clear organic phase is measured at 244 $\mathrm{m} \mu$.

For the assay $\mathrm{CP}, 1 \mathrm{ml}$ of $0.5 \mathrm{~N} \mathrm{NaOH}$ solution is used instead of $1 \mathrm{~N} \mathrm{NaOH}$ solution, and the reaction mixture is neutralized with $1 \mathrm{ml}$ of $0.5 \mathrm{M} \mathrm{NaH} \mathrm{PO}_{4}$ solution. The absorbance of the organic phase is measured at 266 $\mathrm{m} \mu$.

The reagent blanks are run through the same procedure. As Fig. 1 shows, the standard curves were prepared with their solutions ranging from 5 to $50 \mu \mathrm{g}$. Conformity to Beer's law over the entire range of the concentration was obtained.

Colorimetric Method-In a $10 \mathrm{ml}$ measuring flask, $4 \mathrm{ml}$ of the organic phase obtained from the procedure of the UV method, $3 \mathrm{ml}$ of APHS reagent and $1 \mathrm{ml}$ of $\mathrm{H}_{2} \mathrm{SO}_{4}$ reagent are placed. The mixture is heated in a water bath at $70^{\circ}$ for $45 \mathrm{~min}$. After the reaction

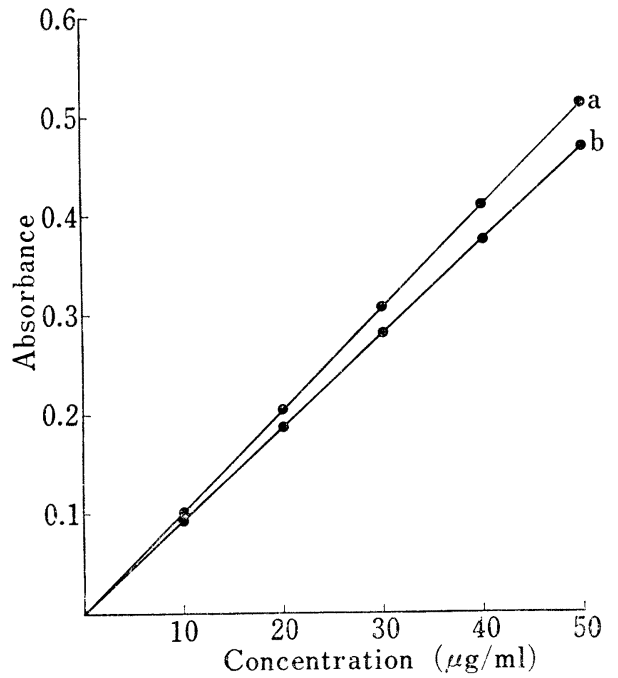

Fig. 1. Relationship between Absorbance and Concentration of Drugs

a: TP (at $244 \mathrm{~m} \mu$ ), b: CP (at $266 \mathrm{~m} \mu)$

mixture has been cooled to room temperature, the produced pigment is dissolved in $0.5 \mathrm{ml}$ of $\mathrm{MeOH}$, and the solution is made up to $10 \mathrm{ml}$ with ethylene dichloride. Five $\mathrm{ml}$ of the violet solution is transferred into a glass-stoppered test tube containing $4 \mathrm{ml}$ of $5 \mathrm{~N} \mathrm{HCl}$, and the mixture is shaken mechanically for $10 \mathrm{~min}$. After centrifugation, the absorbance at $415 \mathrm{~m} \mu$ of the organic phase is measured against a blank prepared through the same procedure. For the assay of $\mathrm{CP}$ the absorbance at $438 \mathrm{~m} \mu$ is measured.

If the more sensitivity is required, $0.5 \mathrm{ml}$ of $\mathrm{HCl}$ reagent is added to $4 \mathrm{ml}$ of the yellow organic phase. Then the absorbance of the resulting blue solution is measured at $590 \mathrm{~m} \mu$. Both the blue dyes obtained from TP and CP have the same absorption maximum at $590 \mathrm{~m} \mu$, as shown in Fig. 2.

The standard curve of each drug was prepared with the solution in concentration from 5 to $50 \mu \mathrm{g} / \mathrm{ml}$. Conformity to Beer's law over the entire range of the concentration was obtained as shown in Fig. 3.

\section{Establishment of Conditions for the Assay of TP and CP by the UV Method}

The procedures described above were obtained after the investigation of some factors which were concerned in the formation of MSBA and NBA and in the development of the final color. The present paper describes mainly the investigation for the assay of TP, since the conditions for the assay of $\mathrm{CP}$, with the exception of the hydrolysis, are substantially the same as TP.

Conditions for the Hydrolysis of TP and CP_C Conditions for the hydrolysis of TP and $\mathrm{CP}$ were established by varing the time and temperature of the reaction and the concentration of alkali or acid solution. 


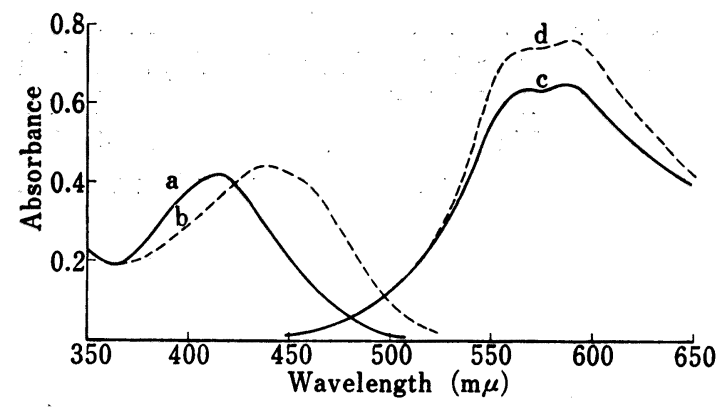

Fig. 2. Absorption Spectra of the Coloring Matters from TP and CP

$$
\begin{aligned}
& \text { a : yellow color (TP, } 40 \mu \mathrm{g}) \\
& \text { b : yellow color (CP, } 40 \mu \mathrm{g}) \\
& \text { c : blue color (TP, } 40 \mu \mathrm{g}) \\
& \text { d : blue color (CP, } 40 \mu \mathrm{g} \text { ) }
\end{aligned}
$$

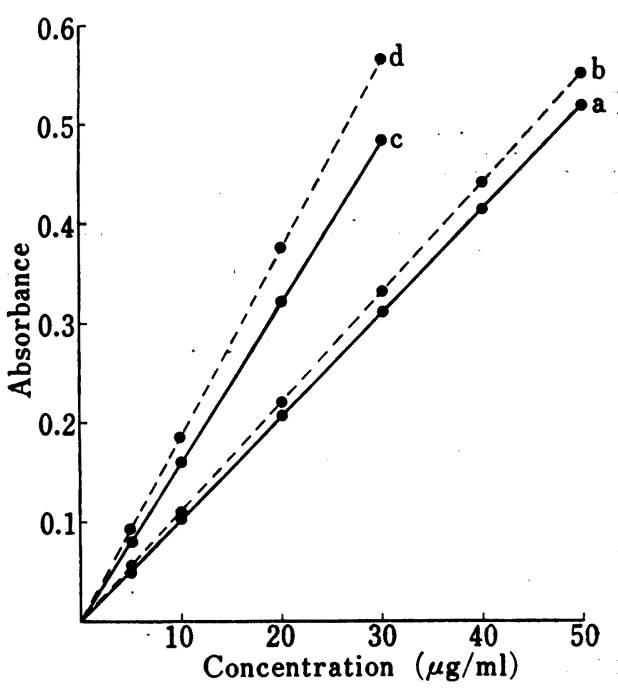

Fig. 3. Relationship between Absorbance and Concentration of Drugs

a: TP (at $415 \mathrm{m \mu}$ ), b: CP (at $438 \mathrm{~m} \mu$ )

c: TP (at $590 \mathrm{~m} \mu)$, d: CP (at $590 \mathrm{~m} \mu$ )

One ml of samle solution containing $50 \mu \mathrm{g}$ of $\mathrm{TP}$ or $\mathrm{CP}$ is pipetted into a glass-stoppered test tube. To the tube is added $1 \mathrm{ml}$ of $\mathrm{NaOH}$ solution or $\mathrm{HCl}$ solution, and the tube is stood at room temperature or heated in a boiling water bath. After the desired time the reaction solution is treated under the same condition as described in the standard procedure of the UV method. The hydrolysis of TP proceeds completely in $5 \mathrm{~min}$ in a boiling water bath with alkali as shown in Fig. 4.

Consequently, the standard procedure adopted $1 \mathrm{~N} \mathrm{NaOH}$ as the reagent and the reaction time of 10 min in a boiling water bath.

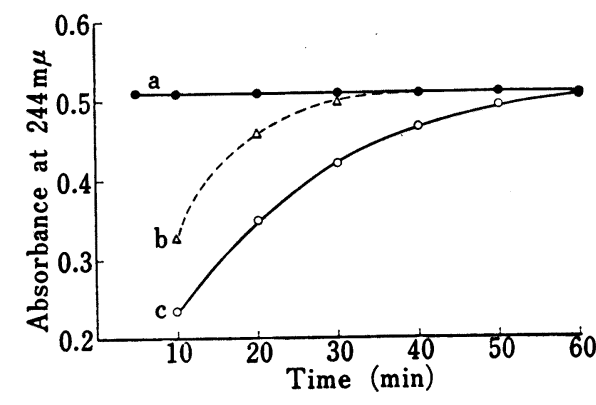

Fig. 4. Hydrolysis of TP

a: $0.25,0.5,1.0$ and $5.0 \mathrm{~N} \mathrm{NaOH}\left(\right.$ at $\left.100^{\circ}\right)$

b : $1.0 \mathrm{~N} \mathrm{NaOH}$ (at room temp.)

c: $6.0 \mathrm{~N} \mathrm{HCl}\left(\right.$ at $\left.100^{\circ}\right)$

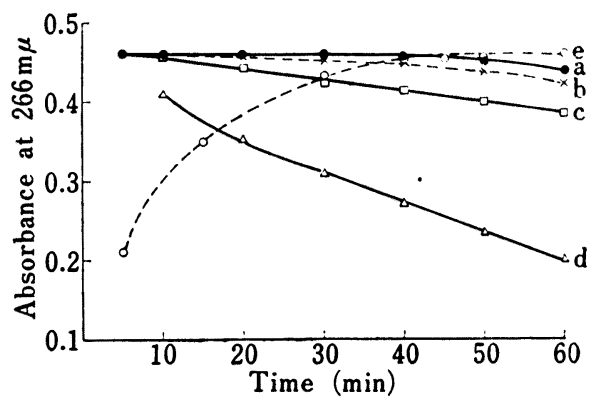

Fig. 5. Hydrolysis of $\mathrm{CP}$

a : $0.25 \mathrm{~N} \mathrm{NaOH}\left(\right.$ at $\left.100^{\circ}\right)$

b : $0.5 \times \mathrm{NaOH}\left(\right.$ at $\left.100^{\circ}\right)$

c: $1.0 \times \mathrm{NaOH}\left(\right.$ at $\left.100^{\circ}\right)$

d: $6.0 \times \mathrm{NaOH}\left(\right.$ at $\left.100^{\circ}\right)$

: $1.0 \mathrm{~N} \mathrm{NaOH}$ (at room temp.)

As Fig. 5 shows, CP is also rapidly hydrolyzed by alkali. However, the continuous decrease in the absorbance of NBA at $266 \mathrm{~m} \mu$ is observed as the time proceeds. This may be attributed to the decomposition of the hydrolyte of $\mathrm{CP}$ to $p$-nitrophenol.6)

6) W. Doll, Arzneimittel-Forshung, 5, 97 (1955). 
In the standard procedure, therefore, $0.5 \mathrm{~N} \mathrm{NaOH}$ solution was used as the reagent for the hydrolysis, and the reaction time for $10 \mathrm{~min}$ in a boiling water bath was adopted.

Conditions for Periodate Oxidation — The optimum condition for the periodate oxidation of the hydrolyte of TP, D-threo-2-amino-1-p-methylsulfonylphenyl-1,3-propanediol, were established by making investigation into the concentration of the reagent, the reaction time and the effect of $\mathrm{pH}$.

Firstly, the effect of the concentration of periodate on the reaction was studied. For this investigation, the hydrolyzed TP solution was prepared as follows. In a $100 \mathrm{ml}$ measuring flask, $10 \mathrm{ml}$ of TP solution $(0.4 \mathrm{mg} / \mathrm{ml})$ and $10 \mathrm{ml}$ of $1 \mathrm{~N} \mathrm{NaOH}$ solution are placed. The mixture is heated in a boiling water bath for $30 \mathrm{~min}$. After cooling, $10 \mathrm{ml}$ of $1 \mathrm{M} \mathrm{NaH}_{2} \mathrm{PO}_{4}$ is added to the mixture and then the mixture is made up to $100 \mathrm{ml}$ with distilled water. The $\mathrm{pH}$ of the solution was about 7.5 to 8.0.

One $\mathrm{ml}$ of the hydrolyzed TP solution is pipetted into a glass-stoppered test tube containing $5 \mathrm{ml}$ of ethylene dichloride, then $3 \mathrm{ml}$ of periodate solution is added into the tube. At the desired time, the mixture is shaken mechanically for 10 min to extract MSBA occurred. After centrifugation, the absorbance of the clear organic phase is measured at $244 \mathrm{~m} \mu$.

As Table Ia shows, the oxidation proceeds rapidly in all experiments. However, the continuous decrease in the absorbance at $244 \mathrm{~m} \mu$ is observed as the time proceeds. This may be due to the oxidation of MSBA with the excess of periodate.

Table $\mathrm{Ib}$ shows the results obtained from the experiment in which the oxidation and the extraction were done simultaneously.

Three $\mathrm{ml}$ of the periodate solution is added as quickly as possible into the reaction tube containing $1 \mathrm{ml}$ of the hydrolyzed TP solution and $5 \mathrm{ml}$ of ethylene dichloride. And then the tube is shaken mechanically. At the desired time, the reaction mixture is centrifuged, and the absorbance of the clear organic phase is measured at $244 \mathrm{~m} \mu$. Under this condition, the absorbance is constant for $40 \mathrm{~min}$ in both concentrations of the periodate solution, 1.25 and $0.01 \%(w / v)$.

TABLE Ia. Effect of Periodate Concentration on the Reaction Time

\begin{tabular}{|c|c|c|c|c|}
\hline \multirow{2}{*}{$\begin{array}{l}\text { Time } \\
(\min )\end{array}$} & \multicolumn{4}{|c|}{ Concentration of $\mathrm{NaIO}_{4}$ solution, $\%(w / v)$} \\
\hline & 1.25 & 0.50 & 0.10 & 0.01 \\
\hline 5 & 0.409 & 0.409 & 0.409 & 0.409 \\
\hline 15 & 0.405 & 0.405 & 0.407 & 0.409 \\
\hline 20 & 0.403 & 0.403 & 0.405 & 0.407 \\
\hline 25 & 0.401 & 0.401 & 0.403 & 0.405 \\
\hline
\end{tabular}

TABLE Ib. Effect of Periodate Concentration on the Reaction Time

\begin{tabular}{rlr}
$\begin{array}{c}\text { Time } \\
(\mathrm{min})\end{array}$ & \multicolumn{2}{c}{$\begin{array}{c}\text { Concentration of NaIO } \\
\text { solution, }\end{array}$} \\
& 1.25 & 0.01 \\
\hline 5 & 0.410 & 0.410 \\
10 & 0.410 & 0.410 \\
10 & 0.410 & 0.409 \\
20 & 0.410 & 0.410 \\
30 & 0.409 & 0.410 \\
40 & 0.410 & 0.410 \\
\hline
\end{tabular}

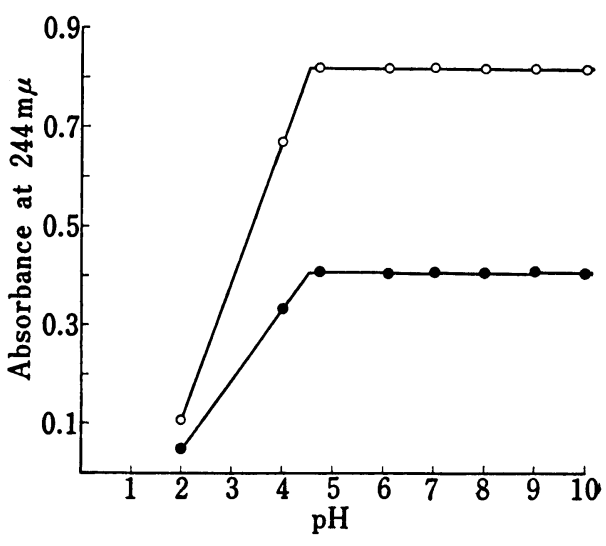

Fig. 6. Effect of $\mathrm{pH}$ on the Periodate Oxidation of Hydrolyzed TP

potassium chloride buffer for $\mathrm{pH} 2.01$; phthalate buffer for $\mathrm{pH} 4.0$ and 4.7; phosphate buffer for pH 6.1, 7.01 and 8.0; borate buffer for $\mathrm{pH} 9.0$ and 10.0

-: $40 \mu \mathrm{g}$ (TP), -O-: $80 \mu \mathrm{g}$ (TP)

In consideration of practical application in biological materials the standard procedure adopted $0.5 \%$ periodate solution and the reaction time for $10 \mathrm{~min}$. 
Effect of $\mathbf{p H}$ on Periodate Oxidation of Hydrolyzed TP__ For this study, the test solution was prepared as follows. Four $\mathrm{ml}$ of the hydrolyzed TP solution in concentrations from $1 \mathrm{mg} / \mathrm{ml}$ to $2 \mathrm{mg} / \mathrm{ml}$ as $\mathrm{TP}$ is diluted to $100 \mathrm{ml}$ with various buffer solutions.

One $\mathrm{ml}$ of the test solution is placed in the reaction tube containing $5 \mathrm{ml}$ of ethylene dichloride. Three $\mathrm{ml}$ of $0.5 \%$ periodate solution is then added to the mixture, and the experiment is carried out under the same conditions as the standard procedure. The $\mathrm{pH}$ of the solution is substantially constant before and after the reaction.

As Fig. 6 shows, at low $\mathrm{pH}$ the reaction did not proceed fully, and did at $\mathrm{pH}$ higher than 4.7 .

\section{Establishment of the Conditions for the Assay of TP by the Colorimetric Method}

This method is based on the reaction of the aldehyde, obtained by the UV method, with APHS reagent in the presence of $\mathrm{H}_{2} \mathrm{SO}_{4}$ reagent to form a violet dye which is turned to a stable yellow color by treatment with $5 \mathrm{~N} \mathrm{HCl}$ solution. The visible light absorption spectrum of the yellow color is shown in Fig. 2.

The yellow color is turned to a stable blue color again by treatment with $\mathrm{HCl}$ reagent. As Fig. 2 shows, its absorbance is about $50 \%$ higher than that of the yellow color.

Effect of Temperature and Time of Reaction and Concentration of $\mathrm{H}_{2} \mathrm{SO}_{4}$ Reagent on Color Development-Firstly, the correlation of temperature and time in the color development was studied.

As Fig. 7 shows, a plateau in the absorbance at $415 \mathrm{~m} \mu$ existed between 40 and $60 \mathrm{~min}$ at $70 \pm 1^{\circ}$.

Fig. 8 shows the relationship between the concentration of $\mathrm{H}_{2} \mathrm{SO}_{4}$ reagent and the reaction time under the standard condition of the colorimetric method. A plateau in the absorbance at $415 \mathrm{~m} \mu$ existed between 40 and $50 \mathrm{~min}$ in the concentration of $12 \%$. Thus, in order to obtain the best reproducibility, the reaction was carried out for $45 \mathrm{~min}$ at $70 \pm 1^{\circ}$, and $12 \%$ (v/v) $\mathrm{H}_{2} \mathrm{SO}_{4}$ reagent was employed.

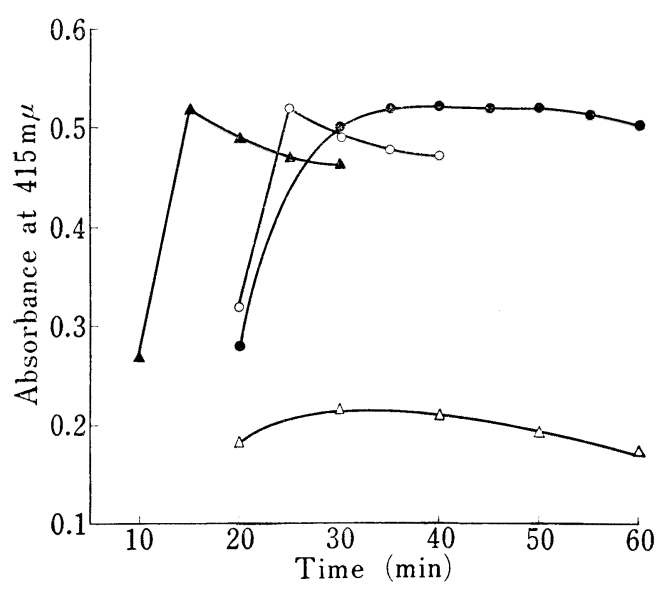

Fig. 7. Effect of Reaction Temperature on Color Development

The test solution is prepared from TP solution (50 $\mu \mathrm{g} / \mathrm{ml}$ ) by the standard procedure of the UV method. Three $\mathrm{ml}$ of $0.025 \%$ APHS reagent and $1 \mathrm{ml}$ of $12 \%(\mathrm{v} / \mathrm{v}) \mathrm{H}_{2} \mathrm{SO}_{4}$ reagent are used. - $\triangle$-: $65 \pm 1^{\circ},-\mathrm{O}-: 70 \pm 1^{\circ}$,
○-: $75 \pm 1^{\circ},-\mathbf{A}-: 80 \pm 1^{\circ}$

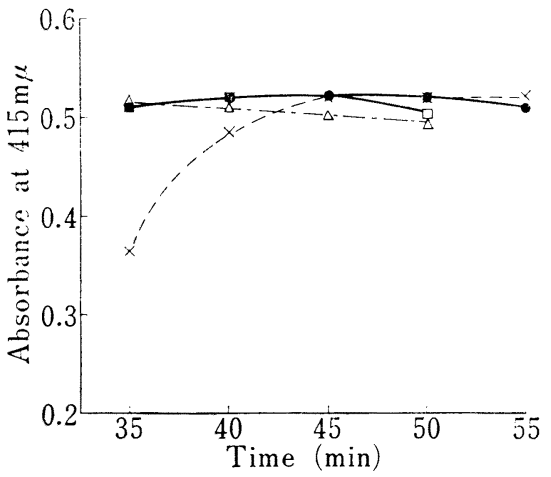

Fig. 8. Relationship between Concentration of $\mathrm{H}_{2} \mathrm{SO}_{4}$ Reagent and Reaction Time

The test solution containing $50 \mu \mathrm{g}$ of TP is treated by the same condition as the standard procedure of the colorimetric method except the concentration of $\mathrm{H}_{2} \mathrm{SO}_{4}$ reagent. $5 \%(\mathrm{v} / \mathrm{v}),-\square-: 10 \%(\mathrm{v} / \mathrm{v})$
$-12 \%(\mathrm{v} / \mathrm{v}),-\mathrm{X}-\mathrm{B}-\mathrm{15} \%(\mathrm{v} / \mathrm{v})$

Concentration of APHS Reagent - The effect of the concentration of APHS reagent on the color development under the same condition as the standard procedure is shown in Fig. 9. 


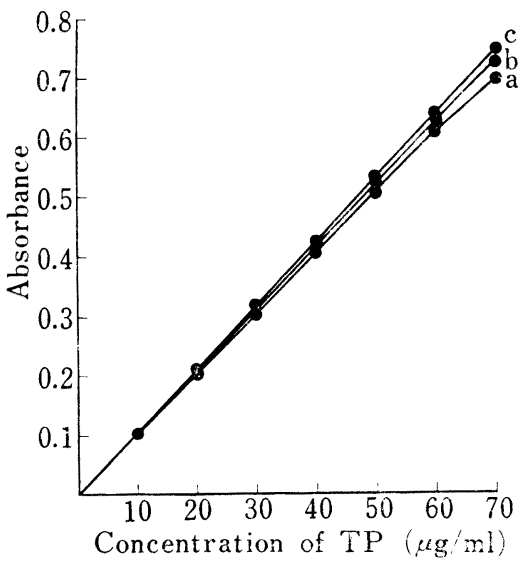

Fig. 9. Relationship between APHS Concentration and Absorbance at 415 $\mathrm{m} \mu$

a: $0.01 \%, b: 0.015 \%$, c: $0.02,0.025$ and $0.03 \%$

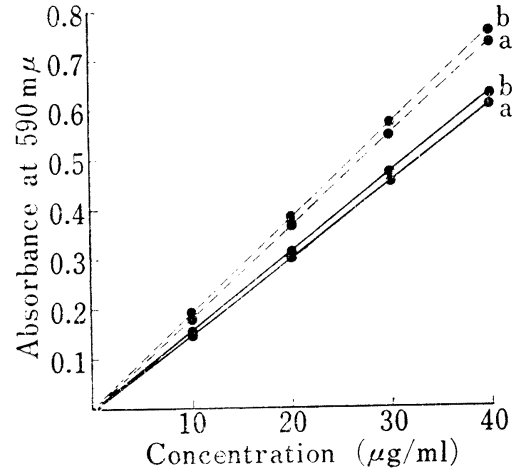

Fig. 10. Relationship between Concentration of $\mathrm{HCl}$ Reagent and Absorbance at $590 \mathrm{~m} \mu$

a: $5 \%(\mathrm{w} / \mathrm{v}), \mathrm{b}: \mathrm{TP}, 7.5,10,15$ and $20 \%(\mathrm{w} / \mathrm{v})$

It indicates that $0.02 \%$ APHS reagent is sufficient for the color development. From the practical view point, therefore, the standard procedure adopted $0.025 \%$ APHS reagent.

Relationship between Absorbance at $590 \mathrm{~m} \mu$ and Concentration of $\mathrm{HCl}$ Reagent - The effect of the concentration of $\mathrm{HCl}$ reagent on the absorbance at $590 \mathrm{~m} \mu$ under the same condition as the standard procedure is shown in Fig. 10.

In order to obtain a sufficient color development, the concentration of $\mathrm{HCl}$ reagent is required above $7.5 \%(\mathrm{w} / \mathrm{v})$. Thus the standard procedure adopted $10 \%(\mathrm{w} / \mathrm{v}) \mathrm{HCl}$ reagent.

Stability of Colors - Table IIa shows that the absorbances at $415 \mathrm{~m} \mu$ for TP and at $438 \mathrm{~m} \mu$ for $\mathrm{CP}$ are constant during the observation period, when the colored solutions are allowed to stand for $60 \mathrm{~min}$ after the color formation.

Table IIb shows that the absorbances at $590 \mathrm{~m} \mu$ for TP and CP could be kept in nearly constant readings during the observation period of $60 \mathrm{~min}$. Therefore, the absorbances . of the colors were measured within $60 \mathrm{~min}$ after the color formation.

TABle IIa. Stability of Color

\begin{tabular}{lccccccc}
\hline \hline & \multicolumn{7}{c}{ Time after the color formation, $\min$} \\
& 10 & 20 & 30 & 40 & 50 & 60 \\
\hline Absorbance at $415 \mathrm{~m} \mu^{a)}$ & 0.415 & 0.414 & 0.415 & 0.415 & 0.415 & 0.415 \\
Absorbance at $438 \mathrm{~m} \mu^{b)}$ & 0.440 & 0.441 & 0.440 & 0.399 & 0.440 & 0.440 \\
\hline
\end{tabular}

a): TP, $40 \mu \mathrm{g} \quad b): \mathrm{CP}, 40 \mu \mathrm{g}$

TABLE IIb. Stability of Color ${ }^{a}$ )

\begin{tabular}{lcccccc}
\hline & \multicolumn{5}{c}{ Time after the color formation, min } \\
& 10 & 20 & 30 & 40 & 50 & 60 \\
\hline $\operatorname{TP}[20 \mu \mathrm{g}]$ & 0.302 & 0.302 & 0.302 & 0.303 & 0.303 & 0.302 \\
$\mathrm{CP}[20 \mu \mathrm{g}]$ & 0.376 & 0.376 & 0.376 & 0.376 & 0.376 & 0.376 \\
\hline
\end{tabular}

a) The absorbances at $590 \mathrm{~m} \mu$ were measured. 


\section{Discussion}

Hitherto two methods have been described in the literature for the chemical assay of TP.

$\mathrm{TP}$ is degraded by alkali hydrolysis, followed by periodate oxidation to give $p$-methylsulfonylbenzaldehyde(MSBA). In the method of McChesney, et al., ${ }^{3)}$ this aldehyde is measured colorimetrically as the alkali salt of its $p$-nitrophenylhydrazone. The procedure, however, is complicate and requires too much time for the assay.

On the other hand, the method of Forist and Madden, depending on the determination of dichloroacetohydroxiamic acid produced by the reaction of TP with alkaline hydroxylamine, ${ }^{93}$ is not adequate for the assay in biological materials because of its insufficient sensitibity.

In this paper, the UV and colorimetric methods for the assay of TP and CP are described.

In the two methods, the UV method is suitable for the rapid determination of TP or $\mathrm{CP}$ in some pharmaceuticals, while the colorimetric method is suitable for the assay of these in biological fluids. Generally, there are normal blanks in the estimation of drugs in biological materials. When the normal blanks interfer with the color development, these should be removed prior to the periodate oxidation by extracting with a polar organic solvent such as ethyl acetate. ${ }^{8)}$

Azobenzenephenylhydrazinesulfonic acid has been used for the detection of aldehydes. ${ }^{4}$ This reagent is, however, considerably unstable even in crystalline state. The present paper proposes its diethanolamine salt(APHS) which is easily obtained in pure crystalline state from each mole of the two components. This new reagent is considerably stable when it is kept in dry state. Its solution in $\mathrm{MeOH}$ is also stable at least for one week.

The yellow dye obtained from APHS reagent and MSBA, or APHS reagent and NBA is turned to the blue color which has absorption maximum at $590 \mathrm{~m} \mu$ by adding $\mathrm{HCl}$ reagent. Its absorbance is about $50 \%$ higher than that of the yellow color. However, in consideration of practical application in biological materials, the yellow color may be quite enough for these assay.

The formation of the blue color may be also applied to separable determination of TP and CP. That is, the sum of TP and CP is determined by the colorimetric method described in this paper, and the assay of $\mathrm{CP}$ in the mixture may be made by the method of Glazko, et al. ${ }^{9)}$

7) A.A. Forist and S.T. Madden, J. Pharm. Sci., 50, 269 (1961).

8) T. Arita, R. Holi, and T. Uesugi, Chemotherapy, 19, 843 (1971).

9) A.J. Glazko, L.M. Wolf, and W.A. Dill, Arch. Biochem. Biophys., 23, 411 (1949). 